In press for 2004. Attachment and Bonding: A New Synthesis

Dahlem Workshop No. 92. C.S. Carter and L. Ahnert (eds).

Cambridge: M.I.T. Press

\title{
EVOLUTIONARY CONTEXT OF HUMAN DEVELOPMENT: THE COOPERATIVE BREEDING MODEL
}

\author{
S.B. Hrdy \\ University of California, Department of Anthropology, Davis, CA 95616-8522, U.S.A.
}

(Nov 15, 2003 version)

\begin{abstract}
According to the Cooperative Breeding Hypothesis, allomaternal assistance was essential for child survival during the Pleistocene. This breeding system - quite novel for an apepermitted hominid females to produce costly offspring without increasing inter-birth intervals, and allowed humans to move into new habitats, eventually expanding out of Africa. Reliance on allomaternal assistance would make maternal commitment more dependent on the mother's perception of probable support from others than is the case in most other primates. One artifact of such conditional maternal investment would be newborns who needed to monitor and engage mothers, as well as older infants and juveniles who needed to elicit care from a range of caretakers across the prolonged period of dependence characteristic of young among cooperative breeders. Implications of this evolutionary context for the sociocognitive and emotional development of infants are explored.
\end{abstract}




\section{Introduction: Moving beyond Bowlby}

John Bowlby was the first evolutionary psychologist to explore how selection pressures encountered by our Pleistocene ancestors (what he termed "the Environment of Evolutionary Adaptedness," or EEA) shaped the development of human infants. In a now classic book on Attachment, Bowlby (1969) drew on personal and clinical experience with Western childrearing, on such evidence as was then available for hunter-gatherer child-rearing as well as for maternal care in other primates - mostly macaques, baboons, and chimps. Based on these sources of information, Bowlby assumed that the mother was the primary, typically exclusive, caretaker in the EEA. In later versions of his book, Bowlby (influenced by Ainsworth and others) mentioned the possibility of multiple caretakers, but he nevertheless continued to center his model on a Victorian division of labor within a pair bond where a sexually monandrous mother nurtured offspring provisioned by their father. But the last quarter century has produced new evidence from primate sociobiology and from the behavioral ecology of foraging peoples that challenges this exclusive "sex contract" between mother and father as the fundamental economic unit for childrearing among our ancestors. Attention began to focus on assistance from group members other than the genetic parents. In the course of an ongoing - still controversial - paradigm shift within Anthropology, the longstanding ideal of an EEA characterized by mother-father child-rearing units is being replaced with a model based on cooperative breeding (Hrdy 1999).

\section{What Is Meant by "Cooperative Breeding"?}

\section{The Study of Cooperative Breeding}

From wild dogs, to elephants, meerkats, marmosets, acorn woodpeckers, and scrub jays, roughly $3 \%$ of mammals, and between 8 and 17\% of bird species (Heinsohn and Double 2004) breed cooperatively. The literature on cooperative breeding in vertebrates is divided between studies of birds, of mammals other than primates, and primates except for humans. While sometimes appropriate, this taxonomic compartmentalization has hindered synthetic analyses and led to a confusing array of taxonomically specific definitions for cooperative breeding. Here, I use a broad and simple definition: a breeding system in which group members other than the genetic parents (alloparents), help one or both parents rear their offspring. Because we rarely know the genetic identity of fathers, it is often more accurate to confine the discussion to allomothers, individuals of either sex who are not the mother. Note that an allomother can be a male, or even the genetic father. Paternal assistance can be complicated in cases like marmosets or wild dogs where not only does more than one possible "father" help, but several males may actually father young in "multiple paternity" litters. More typically, males with different probabilities of paternity adjust their level of care in line with their past mating history with the mother. For example, male dunnocks calibrate food delivery to nestlings in line with how frequently these birds copulated with the mother during the period when she was last fertile (Davies 1992). Male baboons whose partners have mated polyandrously with multiple males, preferentially intervene on behalf of older infants and juveniles likely to be their own (Buchan et al. 2003).

Theoretical Explanations

At a general level, the altruism of alloparents is explained by Hamilton's rule: The cost of helping should be less than benefits to offspring calibrated in line with the alloparent's degree of relatedness to his or her charge. Hence alloparents enhance their inclusive fitness by helping kin. Almost certainly, the neural and physiological underpinnings of helpful motivations first evolved in groups of closely related animals. Tendencies that led individuals to invest in unrelated infants at the expense of closely related infants would be selected against. However there is continuing debate about how important kinship is in maintaining dispositions to help once they have evolved. In particular, complex patterns of migration often mean that male and female helpers are not that closely related yet with varying levels of commitment, they continue to help.

Cooperative breeding was first studied in social insects and birds, animals without lactation where nonmothers are just as equipped to feed young as mothers are. Struck by how much allomothers were helping in hymenopteran social insects, Hamilton (1964) emphasized the unusually high 
degree of relatedness between mothers and helpers. His ideas about kin selection have received strong support. For example, cooperatively breeding carrion crows leave their natal groups and then seek out related individuals, preferring to help kin over non-kin. Today most theorists acknowledge that kinship facilitates the evolution of cooperative breeding, even if it is not necessarily essential to maintain helping behaviors in all contexts. Emlen (1997) has played a major role, emphasizing ecological constraints (such as saturated habitats or predation) that discourage relatives from dispersing. Cooperative breeding is especially likely to evolve where inherited resources are critical for reproduction since maturing animals must queue up. Others emphasize the benefits of philopatry (or remaining in the natal territory). Cockburn (1998) provides the most comprehensive, if aviocentric, review of how helpers might benefit, from (1) enhanced production of nondescendant kin; (2) payment of "rent" allowing access to the territory or other group benefits in exchange for being allowed to stay; (3) opportunistic access to mating opportunities; (4) building up the territory or group in ways that enhance future breeding opportunities; (5) social advancement or better opportunities to signal quality to prospective mates; (6) buying time to mature or acquire skills within the security of a group.

Hence, even unrelated, allomothers may sometimes benefit from caring for infants. For examples, consider the case of help from prereproductives whose own current breeding opportunities are limited. Furthermore, as animals age, and especially as female mammals approach the end of their reproductive careers at menopause, their threshold for helping may decline, while their "donative intent" goes up (e.g. Hrdy 1977 for langurs). In contrast, when physical reserves are at a low point, or when risks rise high, alloparents with prospects of breeding in the future may become less altruistic (e.g. Russell et al. 2003 for meerkats). Still, even helpers with energy to spare or postreproductives with little to loose, should prioritize their service depending on degree of relatedness and especially level of need. The "ideal" allomother's internalized version of Hamilton's rule reads: find infants appealing and help them if you can, so long as cost is not prohibitive and so long as it does not interfere with your own future reproductive career or caring for your own offspring when you have them.

Ecological and Life History Outcomes

Cooperative breeding systems tend to be flexible and dynamic. Often there are one or more mated pairs, but depending on circumstances which fluctuate from one habitat to another, and over the course of lifetimes, a breeding female may mate monogamously, polyandrously (i.e., with several males) or polygynously (sharing her mate with other females). Important features of such systems include delayed dispersal by maturing family members or else migration into the group by non-reproducing (or only occasionally reproducing) adults who are nevertheless responsive to maternal and offspring needs. At a physiological level there has to be sufficient phenotypic flexibility so individuals can shift between non-reproductive and reproductive roles. At a cognitive and emotional level, there has to be some prior predisposition among alloparents to respond to signs of infant need. That is, the underlying neural circuitry has to be there in both sexes and in virgin and parous females (see Fleming, this volume).

As a result of such help usual quantity-versus-quality life history tradeoffs constraining maternal decision-making no longer pertain. This ecological release permits mothers to produce more, larger, or more closely spaced offspring since total cost of rearing each offspring to independence can go up without jeopardizing either her own survival or that of her offspring. Furthermore, reduced opportunity costs from child-rearing along with benefits of group membership, may mean higher rates of maternal survival (e.g. Rowley and Russell 1990). Humans, who exhibit the broadest range of mating permutations ever reported, and also produce some of the costliest infants, have all the earmarks of a cooperative breeder. Compared to other apes, humans take the longest to mature yet human infants are born after shorter intervals. (It was such observations that led anthropologists to devise the "sex contract" hypothesis in the first place.) Since provisioning by alloparents buffers immatures from starvation, it allows populations to move into and spread in new habitats where mothers otherwise would not manage to rear surviving young. Homo erectus which evolved in Africa prior to 1.8 million years ago and quickly spread into 
Eurasia and the Near East exemplifies this pattern.

As early as 1966, Hamilton hypothesized that cooperative breeding would permit slower maturation. A strong correlation between cooperative breeding and prolonged dependence has since been documented in birds. In a sample of 261 species of passerines, 217 never bred cooperatively, 10 did so occasionally, while 34 species were frequent cooperative breeders. Average duration of post-fledging nutritional dependence was significantly longer in cooperative species, and up to twice as long in the obligately cooperative (Langen 2000). Langen attributed these extended periods of nutritional dependence to (1) the reduced cost of parenting produced by a division of labor between helpers who continued to feed youngsters, and mothers who were able to resume breeding; and (2) the fact that provisioned offspring had less incentive to become independent. Logically, these same factors should also pertain in cooperatively breeding mammals. That is, slow maturation combined with short birth intervals would be feasible in cooperatively breeding species such as marmosets and tamarins because allomothers (typically adult males) do so much of the heavy lifting and also help provision infants around the time of weaning. This may explain why when the much smaller size of babies at birth is taken into account, Callitrichids mature at rates almost as slow as those found in humans. Nutritional independence is similarly delayed in other cooperatively breeding mammals where immatures rely on special "baby foods" provided by allomothers. These include regurgitated meat provided to wolf and wild dog pups. In the case of lions and wild dogs, adults allow weaned but still inexperienced young access at pre-butchered kills, subsidizing long apprenticeships.

\section{Primate Preadaptions for Cooperative Breeding, and the Case of male Primability}

So far, members of the subfamily Callitrichidae provide the only "textbook" cases of cooperative breeding among primates, where as in cooperatively breeding birds, allomothers provision as well as carry charges. By two weeks after birth, male Calithrix jacchus - typically former sexual partners of the mother - carry infants (typically twins) up to $60 \%$ of the time. By three weeks, other group members supplement mother's milk by providing small prey, even though the infant will not be weaned until around three months. The more allomaternal assistance available (especially from males), the higher the mother's reproductive success. Saquinus oedipus mothers are so dependent on such help that when kept in naturalistic social groups in captivity, mothers abandoned their newborns if allomaternal assistance was not forthcoming (Bardi et al. 2001). Humans are the only other primates so dependent on alloparental asssistance, characterized by situation-dependent levels of maternal commitment and comparably high rates of maternal abandonment (Hrdy 1999).

Even though members of the subfamily Callitrichidae, and perhaps (if I am right) humans, are the only primates to be classified as full-fledged "cooperative breeders," over all, the Order primates is composed of intensely social species. Many primate attributes predispose them to evolve some degree of shared care-taking. Relevant preadaptations for cooperative breeding range from a primate-wide tendency to be attracted to infants, and to protect infants in the group, to strong urges to hold or carry babies. Benefits of remaining in their natal group can be documented in all primates. These include practical advantages like enhanced knowledge of local resources and protection from predation, as well as social advantages like support from kin. Not surprisingly, the rule of thumb among primates is that those who can remain in their natal troop, do so, thereby enjoying the benefits of social support. Typically it is those who can not afford to stay who must migrate out. A main incentive for leaving is female reluctance to breed with males likely to be close kin, the relevant cue being familiarity from an early age. Males denied sexual access, decamp to find groups of unfamiliar females. Where males resist migrating and stay put, females are pressured to leave rather than breed with kin.

For many primates, especially mothers, remaining among matrilineal kin in multigenerational groups offers special benefits. Enhanced social support brings with it improved vigilance, stress reduction, health, and fitness benefits (e.g., von Holtz 1986; Heinrichs et al. 2003; Silk et al. 2003; Sachser, this volume) that probably increase maternal survival rates. Kin support is especially important for primiparas around the time of first births, an especially vulnerable time for primates 
with universally higher rates of infant loss. Not only does the proximity of matrilineal kin enhance social support, but a mother's greater willingness to allow nulliparous daughters access to their younger siblings, provides inexperienced daughters who remain nearby greater opportunities to practice and prepare for motherhood (Hrdy 1999, pp. 155-164; Fleming, this volume).

Females in all Old World monkeys and apes, as well as in New World monkeys of both sexes, exhibit a "lust" to touch, inspect or carry newborns. The limiting factor is the mother's willingness to allow access. In infant-sharing species like langurs (where in both captivity and the wild, females other than the mother carry infants for up to $50 \%$ of daylight hours), mothers freely give up infants to group members (typically close kin). Even though shared care is species-typical, infant langurs prefer their mothers (with whom they always spend the night) and complain vociferously at being taken away. By contrast to langurs, mothers in other species like rhesus macaques or chimps, deny access (Hrdy 1977). (It is interesting to speculate that if Bowlby had selected langurs as his "model primate" rather than rhesus macaques, attachment theory might have unfolded differently).

Over half of all 175 or so species of primates exhibit some (often rudimentary) form of either biparental care (both mother and father protecting and caring) or shared protection involving allomothers. Such shared care varies from nonexclusive, occasional care (e.g., a male baboon sitting close to an offspring he might have sired, intervening if protection is needed) to care so costly that those providing it temporarily forego opportunities to forage or breed. Among infant-sharing species, shared care frees mothers to forage with the result that they breed at a faster pace (Mitani and Watts 1997).

The level of shared care varies, but underlying neural circuitry for responding to infants (especially signals of vulnerability and need) seems to be universally present. All simian females are attentive to sights and sounds of newborns, and many (especially young females) find newborns magnetically attractive regardless of whether or not they are related to them. By contrast, many male primates (e.g. in chimps or langurs) tend to remain aloof from infants, and even in infantsharing species exhibit little interest in holding babies (Hrdy 1977). Yet in species like titi monkeys or marmosets, holding and carrying newborns is a top male priority. Males in such are be predisposed to caretake. Surprisingly though, even in species of primates which do not normally caretake, males can be primed by experiences to do so although the threshold for responding to infants is set higher (Hrdy 1999, pp. 211-214). Male primability provides an informative case study.

The most interesting findings involve prolactin-mediated systems (Schradin and Anzenberger 1999; Storey et al. 2000). The first hint that there was a correlation between prolactin levels and male care came from marmosets. This report was initially met with skepticism, partly because prolactin was viewed as a maternal hormone, and also because prolactin is involved in stress responses. However the discovery was subsequently replicated using noninvasive techniques. Later still, researchers learned that the rise in prolactin levels was more pronounced among males who had prior caretaking experience (Snowdon 1996).

These were impressive findings, yet it took two decades along with a paradigm shift in the conceptualization of sex roles before researchers asked the same questions about humans. Only then did we learn that men cohabiting with pregnant women and new mothers experience hormonal changes similar to those in cooperatively breeding marmosets (Storey et al. 2000; Fleming et al. 2002; Fleming, this volume). Over the course of a woman's pregnancy, the man's prolactin levels gradually rise. In addition, men exposed to pregnant women and new babies experience a drop in testosterone after birth.

There is little doubt that hormonal changes during pregnancy and lactation are more pronounced in women than men. Except for species with obligate male care like titi monkeys, female primates are more sensitive to infant appeals and signals than males are. No one is suggesting that fathers are equivalent to mothers, male caretakers the same as female ones. Physiological and sensory thresholds of the two sexes are so different that experimenters use different scales to measure them. But the point remains: even in animals with low levels of joint caretaking, both sexes can be primed 
to care. Neither birth, nor even the prospect of giving birth, are prerequisites for nurturing. Virgin females, or males, can be primed to nurture merely by prolonged exposure to infants or pregnant mothers. One possible interpretation is that in our evolutionary past, infants short on care could look to males as well as females to pinch-hit.

\section{Why Humans Must Have Evolved as Cooperative Breeders}

Humans are costly to produce, mature slowly, and rarely reach nutritional independence before age 18 or older. Even with four year or longer birth intervals, a hunter-gatherer mother would have a new offspring before her last one became entirely self-sufficient (Kaplan et al. 2000). Assuming roughly 13 million calories to rear a child from infancy to nutritional independence, such outlays exceed what a mother by herself could provide. Among extant foragers hunting and/or fishing are important sources of protein, but are also risky pursuits. Even when men manage to kill a large animal, meat is typically shared with the group at large rather than channeled to a man's own mate and her offspring. For this reason, mothers who exclusively relied on "husbands" were taking a chance. When fathers die, or defect, have little luck hunting, or when they decide to share what they bring back with the group at large, what kept children from starving? Part of the answer is that many early humans did starve. But which ones survived?

\section{Availability of Allomothers in Pleistocene Societies}

Recently, Hawkes et al. (1998) have focused attention on the role of older matrilineal kin, especially "hardworking" grandmothers studied among Hadza hunter gatherers in Tanzania. In times of food shortage, children with older matrilineal kin on hand, grew better. But as critical as a grandmother (or great aunt) might be, how likely were they to be around? The answer is not knowable. At best, such paleontological and archeological evidence as is available can be used in combination with demographic assumptions derived from extant hunter gatherers, to estimate reasonable demographic profiles for groups under a range of circumstances. Using this methodology, Kurland and Sparks (2003) estimate that under conditions of low mortality, a twentyyear-old primipara would have about a $50 \%$ chance of having a forty-year-old mother alive to help her. If higher mortality rates are used, this probability drops to $25 \%$. Under both mortality conditions, the chance of a new mother having a five year older sibling around would be about twice as high as the chance of having a grandmother. The chances of having one or more cousins would be higher still. In other words, mothers would typically be coping with incomplete kinship sets, although deficits in allomaternal assistance could be offset by compensatory behavior on the part of opportunistic strategists (e.g., a grandmother might move to join the daughter who needed her most, etc.). The need to expand the number of available "kin" may help explain why classificatory kinship systems are so common, as well as why foragers place so much stock in trade networks and other reciprocal relationships (Wiessner 2002). Wiessner argues that one reason besides prestige that a talented hunters would expend effort hunting large game and sharing out the meat (which after all is not the most efficient way to provision his children) is that he thereby influenced the demographic composition and political dispositions of his group. By recruiting group members likely to be both efficient providers and/or generous allomothers, a hunter could enhance the survival chances of kin.

\section{The Debate over Residence Patterns}

Demographic reconstructions of Pleistocene family life rely on assumptions about residence patterns. Based on a two-pronged set of assumptions, it was long taken for granted that early humans lived patrilocally. First, it was taken as gospel that early humans lived in "male philopatric" associations because unlike most mammals, the nonhuman Great Apes were assumed to. Sons remained near father, brothers, and cousins to form alliances of related males who cooperated to protect their access to resources (including breeding females) in their local area. Secondly, Murdock's cross-cultural analyses (1967) indicated that $67 \%$ of the world's cultures lived patrilocally, so it was assumed that Pleistocene humans did so as well. Fairly obviously, if women were moving away to live among their husband's kin, this severely constrained the availability of matrilineal relatives.

However new data suggest that ape females do not necessarily migrate. Based on molecular data, 
wild chimp "brotherhoods" may be no more closely related than females are. Furthermore, longitudinal observations from Gombe reveal that some females manage to remain in their natal territories (Pusey et al. 1997). In particular, the oldest daughter of a dominant female who finds herself in a good situation, may remain to inherit her mother's territory along with her social position, backed up by high-ranking male kin in the area. Females thus privileged reach menarche earlier, breed at shorter intervals, and produce offspring more likely to survive. The new rule of thumb for female chimps is best summarized as "those who can, stay; those who can't leave" (Hrdy 1999). Furthermore, Alvarez (2004) has painstakenly re-examined the original ethnographies used by Murdock (1967) to classify so many foragers as patrilocal. Murdock's criteria were undeniably precise. For example, a society classified as "ambilocal" (or bilocal) had to be one where "residence is optionally established with or near the parents of either the husband or the wife ... where neither alternative exceeds the other in actual frequency by a ratio greater than two to one... ." But nowhere in the ethnographies could Alvarez locate the information needed to make such precise determinations. The majority of Murdock's assignments appear to have been based on hunches. Confining her analysis to those foraging societies with sufficient evidence to confidently assign residence patterns, only one quarter (12 of 48) were patrilocal. Most were bilocal. Because of bride service (where the new husband hunted on behalf of his wife's family for a time), a daughter was likely to remain near her kin until after her first birth. Various strategic maneuvers could increase the availability of kin, even as harsh demographic realities worked to reduce it.

\section{Allomothers Were Not Just Helpful, But Essential, for Survival in the Pleistocene}

According to family historians, early European mothers with supportive matrilineal kin were less likely to abandon their babies, while for contemporary mothers and children, a vast sociological literature attests to the manifold benefits of extended families. Ethnographers too have long stressed the usefulness of child minders in nonwestern societies (Levine et al. 1996; Tronick et al. 1987; Weisner and Gallimore 1977). It scarcely comes as news that supportive kin are helpful. What is new is the proposition that in societies with high rates of mortality, children without allomothers might be significantly less likely to survive. This is the basis for hypothesizing that alloparental assistance represents an ancient way of life integral to human adaptations in the EEA. Nomadic hunter-gatherer mothers would have confronted dilemmas like those that working mothers face today, except that given high rates of child mortality in the Pleistocene, few mothers without alloparental assistance managed to successfully rear offspring.

Early humans are presumed to have lived at low densities, and the remarkable lack of genetic variation among humans compared to chimps, may be due to population crashes and population bottlenecks (although this is not the only interpretation). If early human groups were prone to local extinctions, the most plausible cause would be recurring periods of food shortage. Alternative explanations rely on sources of mortality (warfare or disease) that probably only increased after our numbers did, post-Neolithic. Diseases like malaria, cholera, diarrhea, and tuberculosis did not become big killers until after people adopted sedentary lifestyles and lived at higher densities. Based on what we know about primate mortality from food shortage, immatures - especially those just past weaning - are most susceptible. This would be the age group that benefits most from alloparental assistance. Indeed, data coming in from traditional societies now show that wherever child mortality rates are high, alloparents significantly affect their survival.

The Sibling Factor

One reason why the critical role of allomothers was overlooked was that sociologists studied Western populations with low rates of child mortality. By the end of the 1980s, however, anthropologists influenced by sociobiological studies of animals, began to ask if allomaternal assistance mattered for human reproductive success. In a pioneering study, Turke (1988) found a correlation between the availability of allomaternal assistance and increased maternal reproductive success in a matrilineal, matrilocal Ifaluk population living on Truk. On this Pacific island, parents with a daughter to help rear subsequent children had higher reproductive success than parents whose first two children were sons. About the same time, another sociobiologist, Mark Flinn (1989) reported that Trinidadian mothers in households with non-reproductive helpers - usually daughters 
- had significantly higher reproductive success than mothers without. Neither study involved nomadic foragers, and both suffered from small sample sizes. Furthermore, if mothers with helpers had higher reproductive success than mothers without, how to be sure that this was due to their help? Perhaps some other factor (like more household resources) encouraged non-reproductive helpers to remain, and also enhanced child well being? Nevertheless, this was the beginning.

Accustomed to stratified, patriarchal societies, many of us took for granted that older siblings were a liability who received more parental investment and inherited the bulk of family resources, while younger siblings get short shrift. Indeed, in many Asian societies, a daughter with several older siblings - especially if her family already had older daughters — risked being killed by her parents at birth. We tended to overlook the fact that in less stratified traditional societies, older siblings can be an asset. For example, among horticulturalists living in the Gambia of West Africa, children with older sisters had significantly higher survival chances than did same age children without older sisters (Sear et al. 2002, p. 58). In cases like Ifaluk, the beneficial effects of siblings depended on a precise configuration with daughters born first. Elsewhere though, benefits of older siblings did not show up until later in life, when younger sibs themselves reproduced (e.g., Draper and Hames [2000] for !Kung hunter-gatherers in Botswana). Mechanisms behind this correlation remain unknown. Possibly, adult siblings provide shelter or food in times of crisis, contributing to the survival of nieces and nephews. The point is, collateral kin have the potential to help at various times across the life cycle.

Although the lactating mother would typically be the primary caretaker in the first months, the prospect of allomaternal assistance promotes maternal commitment. Having child minders within easy reach, even inexperienced ones, frees the mother to forage more efficiently. With the approach of weaning, allomothers can offer soft foods to the infant. Experienced grandmothers and greataunts seem to be especially important for the survival of just-weaned infants. For those whose mother is in poor shape or less than fully committed, allomothers can be critical at any age.

Grandmothers as a Special Class of Allomother

Ever since Hawkes et al. (1998) called attention to how hard and efficiently post-reproductive women foraged among the Hadza of Tanzania, data have been accumulating for a broad range of societies documenting increased survival for children with older matrilineal kin nearby. Such data are all the more remarkable because the correlation is found over such a broad spectrum of subsistence conditions. Well documented cases come from African hunter-gatherers; West African horticulturalists (Sear et al. 2002), $18^{\text {th }}$ century German peasants (Voland and Beise 2002) and ricegrowing peasants in $19^{\text {th }}$ century Tokugawa Japan (Jamison et al. 2002). Among patrilocal Bengalis, swidden agriculturalists in northeastern India, grandmothers contribute to shorter birth intervals, while among nearby matrilineal Khasi groups, their presence was correlated with increased child survival (Leonetti et al. 2004; Voland et al. [2004] for overview).

For both German peasants (Voland and Beise 2002) and Gambian horticulturists (Sear et al. 2002), survival advantages from a nearby maternal grandmother showed up around the age of weaning - an especially vulnerable life phase involving emotional stress and the introduction of new foods. The cause is unknown, but the timing points to provisioning by grandmothers. Yet, the Gambia population is primarily Muslim, with mothers living patrilocally in their husband's home. At first glance then, it seems odd that the maternal grandmother's presence mattered so much. Noting how common it is for West African mothers to foster babies out at the time of weaning so babies "forget the breast," Sear et al. suggest that the most solicitous caretaker not already living in the household would be - were she still alive, and near-by — the maternal grandmother.

Once allomothers became essential for child-rearing, selection would have acted on life history traits that made allomothers more available (e.g., delayed dispersal, delayed maturity, longer lifespans). In particular, Hawkes et al. (1998) argued that women's long post-menopausal lifespans evolved because postreproductive women helped provision matrilineal kin, favoring the survival of children whose great aunts and grandmothers were genetically prone to longevity.

How Much Do Fathers Help?

Perhaps the biggest surprise from the Gambia study was how little difference presence of either 
the father or of older brothers made (see also Sugiyama and Chacon 2004). Yet elsewhere, among Ache foragers in South America (Hill and Hurtado 1996), death of the father undermines and infant's survival prospects. Perhaps not surprisingly, in this and other traditional populations in South America, women line up alternative sources of support by identifying "back-up" fathers, relying on a convenient biological fiction known as "partible paternity" to downplay jealousy and increase shared provisioning of young. Not only does the extent to which fathers help vary, but whether or not their help even matters varies.

\section{The Importance of Real and Perceived Allomaternal Support}

Across mammals, the best single predictor of infant survival is maternal commitment. But in humans, this commitment is influenced - at least initially — by the mother's own perception of pre- and post-partum social support. The ethnographic and historical record for societies in which child survival is far less certain than in our own, provides ample evidence that mothers short on allomaternal support are more likely to abandon infants at birth (Hrdy 1999). Even small increases in social support for the mother, enhance how responsive she is to her infant (see Thompson et al., this volume). Adolescent U.S. mothers (even those where the father remains with them), are more sensitive to their infants' needs and have more securely attached infants if a supportive grandmother is also on hand. Even "as if" kin in the persons of visiting nurses can increase maternal responsiveness, and lower the incidence of child abuse in the first two years, with benefits from these early interventions still detectable 15 years later (Olds et al. 1986, 2002). Social workers and medical personnel have long been aware that both mothers and their children derive emotional and material support from extended, multi-generational families. Even when socioeconomic conditions are held steady, rates of child morbidity and mortality rise in single parent homes (Weitoft et al. 2003). When times are tough, presence of allomaternal support may matter even more, for example, if maternal competence is compromised by immaturity, by inexperience, by father absence, or resource scarcity. Beneficial effects also extend to sociocognitive skills. Prospects for children at risk can be improved on a range of measures with the presence of a supportive allomother, whether related (like a grandmother) or an unrelated teacher or mentor (Werner 1984). Furstenburg, for example, found that babies born to unmarried, low-income U.S. teenagers, test better on cognitive development if a grandmother is present (1976). It is time to consider what prompts such individuals to help.

\section{Hamilton's Rule and the Proximate Causes of Helping}

Allomaternal Responsiveness

For cooperative breeding to evolve in the first place, group members must be predisposed to respond to signals of infant need. Most primates are. Females in particular are attracted to babies, and seek to touch, hold or carry them. Across primates, prior caretaking experience matters for competent parenting. Presumably, such baby "lust" evolved to help insure that prereproductives are prepared for parenthood, neurologically primed as well as practiced (Fleming this volume). In infant-sharing primates where females live in matrilineal kin groups, allomaternal assistance keeps the baby safe while the mother is free to forage, contributing to both her fitness and to the inclusive fitness of kin. Males too may be attracted to babies, and in some species (like titi monkeys) have an even lower threshold for responding to them than mothers. To be convinced, one need only watch a male Callithrix argentata hovering near his mate at birth, grabbing at the emerging baby, even vying with the mother to eat the placenta. Males primed by prior experience with babies appear especially eager.

In humans, both sexes respond to infantile behaviors like smiling or babbling, and as first noted by Konrad Lorenz, both sexes are attracted by "cuteness" (round heads, small face, big eyes, immature body form, and obvious vulnerability), but there are significant differences in how the sexes respond (Alley 1983). Although both sexes respond to cuteness, and having a younger sibling increased this responsiveness, on average, women were more protective.

Strategic Calibration of Altruism

In many cooperatively breeding mammals, allomothers schedule assistance so as reduce costs to their own fitness. They are most likely to help when they are too young, or too old, to breed 
themselves, or when for social or ecological reasons, breeding would not be practical. Allomothers may be most eager to help when in good condition, but when resources are scarce or when helping would interfere with their own reproduction, may decline. Simply pretending to help is also an option. Among white-winged choughs, young helpers ostentatiously carry food to nestlings, only to swallow it themselves when parents are not watching (Cockburn 1998:161). There may also be penalties for not helping —including reduced parental tolerance for shirking allomothers. Such generalizations apply in spades to humans where social sanctions operate in many subtle, and not so subtle, ways and among whom pay-offs from generosity and kindness come in many currencies.

\section{Implications of the Cooperative Breeding Hypothesis for Human Development}

A heritage of cooperative breeding has profound implications for psychological adaptations across a broad range of life phases. This topic has only begun to be explored. For example, even though human mothers like other apes produce singleton young after a long period of gestation, if human mothers evolved as cooperative breeders, women and their infants should theoretically have been selected to seek and elicit support from a range of individuals. This has repercussions for the psychobiological underpinnings of male-female, female-female, infant-mother, and infantallomother relationships. Here I focus on the implications for the emotional and cognitive development of infants.

Primates produce costly singleton births. Quality control is built into the process at many levels. Only adequately nourished mothers ovulate, only selected ovulations are fertile, only a single successful sperm is selected, only viable conceptions persist, and so forth. Once they give birth, nonhuman primates are predisposed to carry and care for any infant vigorous enough to catch hold of the mother's fur, reach her nipples, and initiate lactation. Once born, even blind or seriously deformed neonates are carried so long as they can cling. Even a stillborn infant may be carried at least for a few hours. In hundreds of thousands of hours of observations, abandonment of full-term infants by their mothers has rarely been observed in wild primates, and mothers in the wild have almost never been observed to deliberately hurt their own infants. (Exceptions involve inexperienced primiparae, anxious mothers trying to restrain infants, or mothers who punish offspring they are trying to wean, and with the exception of incompetence such behaviors never result in injury). Apart from inexperienced primiparae, abandonment only occurs under extreme duress (e.g., mother in very poor condition; infant threatened by infanticidal males). However there are two groups of primates to which these generalizations do not apply, cooperatively breeding Callitrichids and humans. In both, maternal commitment is unusually contingent on social circumstances. Like tamarins, human females respond to lack of support by failing to commit in the period right after birth, reducing or terminating investment in a newborn by abandoning it, or outright infanticide. Furthermore, human mothers are the only primates who have become discriminating about which infants they invest in, using criteria like sex, birth order, and viability (including birth weight and whether the baby appears full term; for review of vast ethnographic, historical, and ethological literatures on maternal abandonment and infanticide in humans see Hrdy 1999).

\section{Selection Pressures on Neonates Produced by Contingent Maternal Commitment}

If human mothers are more discriminating about which babies they invest in, neonates that conform to maternal preferences would have been more likely to survive. Maternal preferences for babies that look plump and full term may explain why human infants are born fatter at birth than other primates. (The main alternative hypothesis has to do with the demands of brain growth, but this does not explain why fat is stockpiled prior to the difficult birth process). Infants who engage their mothers right from birth would have an advantage over those who do not. Contingent maternal commitment meant that compared to other apes, human infants had a greater need to monitor and interpret the moods and intentions of others, and if a caretaker seems likely to disengage, to work harder at engaging her.

Beyond clinging and the cries that baby apes emit when uncomfortable or separated, newborn humans seek out human-like faces and initiate contact with others. Soon after birth, human apes 
imitate faces, smile, and laugh in ways that have never been observed among wild ape. Human babies are born with white sclera (not seen in other apes) that highlight the direction of their gaze. The extraordinary eagerness of human newborns to seek out faces and connect with eyes, well described by Baron-Cohen (1995) may reflect their need to monitor, attract, and engage mothers. (Indeed, in a remarkable set of experiments, increased eye contact, mutual face gazing, and more smiling was elicited in baby chimps by inserting a human allomother into the mother-infant dyad, Matsuzawa 2001; Bard in press). At the same time, sociocognitive skills thereby developed, can also serve to attract allomothers later on, opening further possibilities.

\section{The Need to Attract Allomothers and Selection Pressures on Older Infants}

A baby's primary source of information about his world would be the mother and her reactions to her world. But if humans evolved as cooperative breeders, infants also needed to be sensitive to social support cues in their immediate community. Such cues would inform internal working models (see Kraemer et al., this volume), but also physiological "decisions" such as how fast to grow. When infants feel confident of continued succor, they should invest in rapid growth. Alternatively, indifference or neglect might signal that this was a time for the child to shut down growth, conserving resources and increasing the chances of surviving future neglect, one explanation for why children with adequate food nevertheless "fail to thrive."

Human babies are born "connoisseurs" of solicitude. Even with the onset of weaning, early learning biases persist, developing with age and experience. As a baby becomes more discriminating about which caretakers to trust, his ability to predict the behavior of others is further refined and reinforced (Tomasello 1999). Good mind readers become better mind readers (Baron-Cohen 1995). Human infants seek out, fixate on, and engage with eyes, and preferentially respond to a direct gaze. By three to four months human infants smile less at adults who avert their gaze, but resume smiling when the adult looks straight at them (Farroni et al. 2002). Such propensities and socio-cognitive tools for monitoring others and reading their intentions by seeking out their eyes, following their gaze, etc. are not so well developed in other apes (Baron-Cohen 1995; pers. obs.). Evidence from field and lab (summarized by Whitten et al. 2003) suggests that chimps are capable of reading intentions and learning through observation and imitation, but by three to four years humans are more adept at doing so, and more eager to. Children freely imagine what it is like to be someone altogether different, even someone they have never seen, enjoy doing so, and delight in drawing others into this game (Harris 2000; Trevarthen, this volume). This greater interest in "inter-subjectivity", in understanding what and why someone else is trying to do something (Henninghausen and Lyons-Ruth, this volume), coupled with an eagerness to share goals with others, improves our ability to learn through observation. It makes humans especially prone to accumulate and transmit new knowledge (Tomasello 1999). Both Baron-Cohen and Chisholm (2003) propose that such mental aptitudes for mind-reading would be valuable for predicting and interpreting the intentions of others, and hence in affecting their behavior. But why should humans have been selected to be so much better at this than chimps are?

\section{Why Humans are so cooperative and "hyper-social"}

According to proponents of the "Machiavellian intelligence" hypothesis (Byrne and Whitten 1985), reading minds provides a strategic advantage in competitive worlds characterized by shifting alliances. But given that many primates, and all other apes, also live in complexly competitive societies, the need for Machiavellian intelligence fails to explain why humans should be so much better at imagining the intentions of others and moving into their conceptual worlds, than other apes are. Chimps, after all, are at least as dominance-oriented and competitive as humans are, probably more so. So why should capacities for shared engagement be so much better developed in humans, why should humans be (following Tomasello 1999) so "hyper-social"? And eventually too, so hyper-altruistic (e.g., Fehr and Fischbacher 2003)? What most distinguishes humans from other apes is not so much our competitive heritage as our more cooperative one.

Infants born into cooperative breeding systems depend on a range of caretakers, and maternal 
commitment itself is contingent on the mother's perception of how much support from allomothers she is likely to have. To prosper in such a system, infants have to be adept at monitoring caretakers, reading their moods and intentions, and eliciting their solicitude. Chisholm (2003) argues that "theory of mind" reduces the uncertainties youngsters face, helping them to predict how others (both mothers and allomothers) are likely to respond. Through practice and conditional rewards, infants get incrementally better at reading intentions and learning to engage caretakers. This explains why infants with older siblings are better able to interpret the feelings and intentions of others (Ruffman et al. 1998). ${ }^{1}$

In the case of creatures as intelligent and manipulative as all apes are, precociously expressed abilities to read and interpret the intentions of others continue to develop through the first years of life. There is a racheting effect as early efforts develop into sophisticated mind-reading (Tomasello 1999, p. 67; Baron-Cohen 1995). Being able to intuit and care about what others are thinking, to cognitively and emotionally put oneself in someone else's shoes, and think about what they are thinking, to play with them, learn from them, and share their goals (Trevarthen, this volume), has in turn had spectacular repercussions in the evolution of our peculiarly "hyper-social," information-sharing and culture transmitting species (Tomasello 1999). That is, neural underpinnings for mind-reading are laid down in early and later infancy and provide the necessary underpinnings first for empathy, and then for development of full-fledged Theory of Mind a few years later, usually between ages four to six. Once such traits were expressed in the phenotype, natural selection would have had an opportunity to favor any small changes in genes or gene expression that predispose the organism to develop them (West-Eberhard 2003).

Continuing in this speculative vein, I am struck by other unusual traits that humans share with cooperative breeders. Against all phylogenetic predictions, dogs can be better at extracting information from human social signals than are chimps (with the exception of chimps reared in close contact with humans). In an ingenious set of experiments, Hare et al. (2003) demonstrated that dogs (and even puppies not yet exposed to humans) were more skillful than chimps at using human social cues like direction of gaze, finger pointing and finger tapping, to locate containers with hidden food. (Experimenters controlled for smell). How could this be? Not only do dogs descend from cooperatively breeding wolves - and so are presumably neurologically equipped to read intentions - but domestic dogs also have a fifteen thousand year history of co-evolving with humans. In this sense, the social environments of dogs were evolutionarily comparable to those of children. Both depended on tolerance and handouts from larger, food-possessing human allomothers.

Babbling, the repetitive, rhythmical vocalizations long assumed to be uniquely human, represents the strangest of all such convergences. Babbling spontaneously emerges around seven months, about the same time that babies begin to grow "milk" teeth, beginning with two tiny incisors at the bottom, then four more on top. This is about the time that babies begin to distinguish familiar people from strangers, and to accept pre-weaning foods. By age three or so there will be twenty sharp little teeth to help babies chew their first solids, mostly soft or mashed foods, or food premasticated by someone else. Babbling, as it turns out, is not unique to humans. Something like babbling crops up in Callitrichids, the only primates (besides humans, if I am right) with fullfledged cooperative breeding. In pygmy marmosets, babbling emerges between the first and third weeks, just about the time allomothers take over most of the care (Snowdon 2001). It seems likely that babbling in human babies, like smiling, originated for the same reason that babbling developed in Callitrichids. For babbling (and the rhythmic movements of hands and feet that accompany it in humans) attracts the attention of caregivers and elicits interest, solicitude, and edible tidbits. Even as adults Callitrichids continue to use vocalization as a means of locating and staying in contact with other group members. They engage in far more contact vocalizations than do chimps or other apes - with the exception of humans (Snowdon 2001).

It has long been assumed that infants babble because the practice helps them learn to talk. No doubt it does. But I suspect that babbling evolved before language, and for a different reason. Our ancestors were born clever apes who because they needed to engage caretakers babbled at them. 
Best babblers were best fed, and also learned to talk, thus entering into a world of new possibilities. Of course long childhoods are critical for such skills to develop, but longer periods of nutritional dependency are predictable corollaries of alloparental provisioning. According to this scenario, opportunities provided by slow development were in place before the evolution of sapient brains. Cooperative breeding in a species so clever as an ape was the novel feature of this experiment.

Dependence on allomaternal assistance produced more contingent maternal commitment and with it the need for babies born scanning and monitoring signals of commitment from those around them, equipped from birth and through childhood to engage and elicit investment from mothers and others. Present such a talented ape with a long, well buffered phase in which to develop, and novel coevolutionary processes are likely to be unleashed.

\section{Long Childhoods}

To the extent that anthropologists thought about childhood, most viewed it as a unique stage in the life history of human beings which evolved some two million years ago to provide extra time for developing large brains and for learning. According to this view the evolution of childhood and adolescence, the human capacity for symbolic language, and culture are the result of the inclusion of new life stages in human development. From a comparative sociobiological perspective, however, prolonged post-weaning or post-fledging dependence is a predictable corollary of allomaternal provisioning. Regardless of how big and costly their brains were, and even without the need to acquire special cognitive skills for complex tool use, language and symbolic culture (all the uniquely human traits that long childhoods supposedly evolved to facilitate), early humans would be expected to take their time growing up. Other cooperative breeders far less brainy than we are like crested magpie jays and wolves - also have long "childhoods." Nor do I think it is a coincidence that animals like the Caledonian crow that amaze us with their problem-solving and tool use (Chappell and Kacelnik 2002) are found in taxa with long histories of cooperative breeding.

Conventional explanations for the evolution of sapient brains emphasize the (undeniable) subsistence benefits of tools (Kaplan et al. 2000), or else the social and reproductive benefits of Machiavellian intelligence. However, other group-living apes stand to benefit from tools. After all, chimps use tools to obtain massive amounts of calories from nuts that they have laboriously learned to crack open. They too would benefit from enhanced learning. Yet chimps never evolved humansized brains - why not? Because brains are energetically extremely costly and any delay maturing risky (Aiello and Wheeler 1995). How could a chimp just a little better at nut-cracking gain sufficient reproductive rewards to make delayed maturation and a little bit bigger brain worth it? The slightly dumber nutcracker, would still be likely to outbreed him.

It is difficult to explain why such skills evolved only in the line leading to humans without knowing just what distinguished prehominids from other apes. The proposal made here is that the distinguishing condition was a reliance on allomaternal assistance, and with it (1) contingent maternal commitment (along with the sociocognitive capacities infants need to engage caretakers); and (2) the slow maturation that comes as a corollary of cooperative breeding. If the time til nutritional independence was already delayed, metabolically costly big brains would evolve at a discount. By this logic, long periods of dependency preceded the co-evolutionary processes that selected for bigger and bigger brains and other trademarks of our "hyper-social" species. Among prehominid creatures who already possessed rudimentary theories of mind, and among whom greater intelligence did not have to compensate its possessors for the entire cost of delayed maturation, even small reproductive payoffs from being smarter would be sufficient to favor bigger brains.

\section{Outstanding Questions about Infant Needs}

The cooperative breeding hypothesis relies on a number of assumptions. Is social support really as important for human maternal commitment as assumed here? Are humans really different from other apes in this respect? Will the paleontological record confirm the prediction that long childhoods and delayed maturation precede expansion to sapient-sized brains, elaborate tool kits, and expansion out of Africa? Questions of particular relevance to this workshop, however, have to do with infant development. 
We know from classic studies of hunter-gatherer childcare by Konner, Hewlett, Lamb, Ivey, Tronick, and others that !Kung and Ache babies are primarily held by mothers, while Aka and Efé babies are frequently held by allomothers (see Hewlett and Lamb 2004). It is impossible to know which pattern was more typical of Pleistocene families, although I think we can know how easily infants learn to prefer one specific caretaker. Usually, this is the mother. But to reconstruct Pleistocene family lives, we need more. For example, right from birth newborn langurs are carried by a range of allomothers. Babies cling like glue to whichever female has them even though they unabashedly prefer their mothers. Without the field observations (which we also lack for the Pleistocene), using infant predilections to reconstruct langurs' care-taking system would, by themselves, lead to the wrong conclusion about who cared for babies in these animals.

Accepting Bowlby's central premise about the importance of "a secure base," what options exist for providing a sufficiently secure base for adequate? optimal? particularly desired? outcomes (which one is a whole other issue). To date, most attachment research has relied on assumptions about the naturalness of more or less exclusive maternal care (but see Sagi et al. 1995; Ahnert et al. 2000; Grossmann and Grossman, this volume; Ahnert, this volume). To date, most studies compared mother-care with institutionalized daycare. Yet, the cooperative breeding hypothesis suggests that we should assume an EEA peopled by an array of potential caretakers. Assuming that Pleistocene babies developed in a world surrounded by familiar allomothers, rarely encountering strangers, how did (and how do) babies differentiate? I would like future research in developmental psychology to explore cues infants use for designating someone as "kin" (or at least, as-if kin). How familiar does an allomother have to be? As in other mammals, infants are monitoring smells and facial expressions. What role do other processes, like phenotype-matching or dialect monitoring, play in distinguishing "allomothers" from strangers? I want to know more about infant comfort levels with different allomaternal regimens at different developmental ages. According to this new theoretical perspective, we should be asking about the different effects of a range of allomothers entering the lives of infants and children at various ages. But how many allomothers? At which ages? For how long? It is a theoretical framework that takes "other care" for granted and focuses on making "other" care better.

\section{Acknowledgments}

I am indebted to Jim Chisholm, Barry Hewlett, Kristen Hawkes, Mel Konner and Michael Lamb for discussion over many years about ideas presented here. Specific suggestions from Jim Leckman and Karin Grossman were gratefully included in the final version.

\section{REFERENCES}

Ahnert, L., M. Lamb, and K. Seltenheim. 2000. Infant-care provider attachments in contrasting child care settings. I. Group-oriented care before German reunification. Infant Behav. Dev. 23:197-209.

Aiello, L., and P. Wheeler. 1995. The expensive tissue hypothesis. Curr. Anthro. 36:199-221.

Alley, T. 1983. Growth-produced changes in body shape and size as determinants of perceived age and adult caregiving. Child Dev. 54:241-248.

Alvarez, H. 2004. Residence groups among hunter-gatherers: A view of the claims and evidence for patrilocal bands. In: Kinship and Behavior in Primates, pp. 400-442, ed. B. Chapais and C. Berman. Oxford: Oxford Univ. Press.

Baron-Cohen, S., ed. 1995/2001. Mindblindness: An Essay on Autism and Theory of Mind. Cambridge, MA: MIT Press.

Bard, Kim. In press. Emotions in chimpanzee infants: The value of a comparative developmental Approach to understand the evolutionary bases of emotions. In: Emotional Develompent:

Recent research advances. J. Nadel and D. Muir (eds.). Oxford: Oxford University Press.

Bardi, M.; A. Petto; and D. Lee-Parritz. 2001. Parental failure in captive cotton-top tamarins

(Saguinus oedipus). Am. J. Primatol. 54:150-69.

Bowlby, J. 1969. Attachment and Loss: Attachment. New York: Basic.

Bowlby, J. 1982. Attachment. 2d ed. Attachment and Loss, vol. 1. New York: Basic/Harper Collins.

Buchan, J.C., S.A. Alberts, J.B. Silk, and J. Altmann. 2003. True paternal care in a multi-male primate society. Nature 425:179-181.

Byrne, R.W., and A. Whitten. 1985. Machiavellian Intelligence: Social Expertise and the Evolution of Intellect in Monkeys, Apes and Humans. Oxford: Clarendon.

Chappell, J., and A. Kacelnik. 2002. Selectivity of tool length by New Caledonian crows. Anim. Cogn. 5:71-78.

Chisholm, J. 2003. Uncertainty, contingency and attachment: A life history theory of theory of mind. In: From Mating to Mentality: Evaluating Evolutionary Psychology, ed. K. Sterelny and J. Fitness, pp. 125-154. Hove: Psychology Press.

Cockburn, A. 1998. Evolution of helping behavior in cooperatively breeding birds. Ann. Rev. Ecol. System. 29:141-177.

Davies, N. 1992. Dunnock Beahviour and Social Evolution. Oxford: Oxford Univ. Press. 
Draper, P., and R. Hames. 2000. Birth order, sibling investment and fertility among the Ju/'hoansi (!Kung). Hum. Nat. 11:117-156. Emlen, S.T. 1997. Predicting family dynamics in social vertebrates. In: Behavioural Ecology: An Evolutionary Approach, ed. J.R. Krebs and N.B. Davies, pp. 228-53. 4th ed. Oxford: Blackwell.

Farroni, T., G. Csibra, F. Simion, and M. Johnson. 2002. Eye contact detection in humans from birth. Proc. Natl. Acad. Sci.USA 99:9602-0605.

Fehr, E., and U. Fischbacher. 2003. The nature of human altruism. Nature 425:785-791.

Fleming, A.S., C. Corter, J. Stallings, and M. Steiner. 2002. Testosterone and prolactin are associated with emotional responses to infant cries in new fathers. Horm. Behav. 42:399-413

Flinn, M.V. 1989. Household composition and female reproductive strategies in a Trinidadian village. In: The Sociobiology of Sexual and Reproductive Strategies, ed. A.E. Rasa, C. Vogel, and E. Voland, pp. 206-233. London: Chapman and Hall.

Furstenburg, F. 1976. Unplanned Parenthood: The Social Consequences of Unplanned Parenthood. New York: Free Press.

Hamilton, W.D. 1964. The genetical evolution of social behaviour. 1. J. Theor. Biol. 7:1-18.

Hamilton, W.D. 1966. The moulding of senescence by natural selection. J. Theor. Biol. 12:12-45.

Hare, B., M. Brown, C. Williamson, and M. Tomasello. 2003. The domestication of social cognition in dogs. Science 298:1634-1636.

Harris, P. 2000. The Work of the Imagination. Oxford: Blackwell.

Hauser, M.D., M.K. Chen, F. Chen, and E. Chuang. 2004. Give unto others: Genetically unrelated cotton-top tamarins preferentially give food to those who altruistically give food back. Proc. Roy. Soc. Lond. B, in press.

Hawkes, K., J.F. O'Connell, N.G. Blurton Jones, E.L. Charnov, and H. Alvarez. 1998. Grandmothering, menopause, and the evolution of human life histories. Proc. Natl. Acad. Sci. USA 95:1336-1339.

Heinrichs, M., T. Baumgartner, C. Kirschbaum, and U. Ehlert. 2003. Social support and oxytocin interact to suppress cortisol and subjective responses to psychosocial stress. Biol. Psychiatry, in press.

Heinsohn, Robert and Michael C. Double (2004). Cooperate or speciate: New theory for the distribution of passerine birds. Trends in Ecology and Evolution 19(2):55-60.

Hewlett, B., and M. Lamb, eds. 2004. Hunter-Gatherer Childhood. Hawthorne, NY: Aldine de Gruyter.

Hill, K., and A. Hurtado. 1996. Ache Life History: The Ecology and Demography of a Foraging People. Hawthorne, NY: Aldine de Gruyter.

Hrdy, S.B. 1977. The Langurs of Abu: Female and male strategies of reproduction. Cambridge: Harvard University Press.

Hrdy, S.B. 1999. Mother Nature: A History of Mothers, Infants and Natural Selection. New York: Pantheon.

Ivey, P.K. 2000. Cooperative reproduction in Ituri forest hunter-gatherers: Who cares for Efe infants? Curr. Anthro. 41:856-866.

Jamison, C.S., L.L. Cornell, P.L. Jamison, and H. Nakazato. 2002. Are all grandmothers equal? A review and a preliminary test of the "grandmother hypothesis" in Tokugawa, Japan. Am. J. Phys. Anthro. 119:67-76.

Kaplan, H., K. Hill, J. Lancaster, and A.M. Hurtado. 2000. A theory of human life history evolution: Diet, intelligence and longevity. Evol. Anthro. 9:156-185.

Langen, T.A. 2000. Prolonged offspring dependence and cooperative breeding in birds. Behav. Ecol. 11:367-377.

Leonetti, D., D.C. Nath, N.S. Hemam, and D.B. Neill. 2004. Kinship organization and grandmother's impact on reproductive success among the matrilineal Khasi and patrilineal Bengali of N.E. India. In: Grandmotherhood: The Evolutionary Significance of the Second Half of Female Life, ed. E. Voland, A. Chasiotis, and W. Schiefenhoevel. Piscataway: Rutgers Univ. Press, in press.

Levine, R., S. Dixon, S. LeVine et al. 1996. Child Care and Culture: Lessons from Africa. Cambridge: Cambridge Univ. Press.

Matsuzawa, Tetsuro. 2001. The baby and Ai. Film made by Primate Research Institute, Kyoto, Japan. Distributed by Mico.

Mitani, J.C., and D. Watts. 1997. The evolution of non-maternal caretaking among anthropoid primates: Do helpers help? Behav. Ecol. Sociobiol. 40:213-240.

Murdock, G.P. 1967. Ethnographic Atlas. Pittsburgh: Univ. of Pittsburgh Press.

Pusey, A., J. Williams, and J. Goodall. 1997. The influence of dominance rank on the reproductive success of female chimpanzees. Science 277:828-831.

Olds, D., C.R. Henderson, R. Chaberlin, and R. Tatelbaum. 1986. Preventing child abuse and neglect: A randomized trial of nurse home visitiation. Pediatrics 78:65-78.

Olds, D., J. Robinson, R. O’Brien et al. 2002. Home visiting by paraprofessionals and by nurses: A randomized controlled trial. Pediatrics 110:486-496.

Rowley, I. and E. Russell. 1990. Splendid fairy wrens: Demonstrating the importance

Of longevity. In: Cooperative Breeding in Birds. P. Stacey and W. Koenig(eds).

Cambridge: Cambridge University Press, pp.3-30.

Ruffman, T., J. Perner, M. Naito, L. Parkin, and W. Clements. 1998. Older (but not younger) siblings facilitate false belief understanding. Dev. Psychol. 34:161-174.

Russell, A.F., L.Sharp, P. Brotherton, and T.H. Clutton-Brock. 2003. Cost minimization by helpers in cooperative vertebrates. Proc. Natl. Acad. Sci. USA, 100:3333-3338.

Sagi, A., M. Van IJzendooorn, O. Aviezer et al. 1995. Attachments in a multiple-caregiver and multiple-infant environment: The case of the Israeli kibbutzim. Mono. Soc. Res. Child Dev. 60:71-91.

Sear, R., F. Steel, I. McGregor, and R. Mace. 2002. The effects of kin on child mortality in rural Gambia. Demography 39:43-63.

Schradin, C., and G. Anzenberger. 1999. Prolactin, the hormone of paternity. News Physiol. Sci. 14:221-331.

Silk, J.B., S.C. Alberts, and J. Altmann. 2003. Social bonds of female baboons enhance infant survival. Science 302:1231-1234.

Snowdon, C. 1996. Infant care in cooperatively breeding species. Adv. Stud. Behav. 25:643-689.

Snowdon, C.T. 2001. From primate communication to human language. In: Tree of Origin, ed. F. de Waal, pp. 195-227. Cambridge, MA: Harvard Univ. Press.

Storey, A., C.J. Walsh, R.L. Quinton, and K.E. Wynne-Edwards. 2000. Hormonal correlates of paternal responsiveness in new and expectant fathers. Evol. Hum. Behav. 21:79-95.

Sugiyama, L. and R. Chacon. 2004. Juvenile responses to household ecology among the Yora of Peruvian Amazonia. In: Hunter Gatherer Childhood. B. Hewlett and M. Lamb, eds. Hawthorne, N.Y.: Aldine de Gruyter. 
(in press).

Tomasello, M. 1999. The Cultural Origins of Human Cognition. Cambridge, MA: Harvard Univ. Press.

Tronick, E.Z., G.A. Morelli, and S.A. Winn. 1987. Multiple caretaking of Efé (pygmy) infants. Am. Anthropologist 89:96-106.

Turke, P. 1988. "Helpers at the nest": Childcare networks on Ifaluk. In: Human Reproductive Behaviour: A Darwinian Perspective, ed. L. Betzig, M. Borgherhoff Mulder, and P. Turke, pp.173-188. Cambridge: Cambridge Univ. Press.

Voland, E., and J. Beise. 2002. Opposite effects of maternal and paternal grandmothers on infant survival in historical Krummhoern. Behav. Ecol. Sociobiol. 52:435-443.

Voland, E., A. Chasiotis, and W. Schiefenhoevel, eds. 2004. Grandmotherhood: The Evolutionary Significance of the Second Half of Female Life. Piscataway: Rutgers Univ. Press.

Von Holst, D. 1986. Psychosocial stress and its pathophysiological effects in tree shrews (Tupaia belangeri). In: Biological and Psychological Factors in Cardiovascular Disease, ed. T.H. Schmidt, T.M. Dembroski, and G. Blumchen, pp. 476-489. Heidelberg: Springer.

Weisner, T., and R. Gallimore. 1977. My brother's keeper: Child and sibling caretaking. Curr. Anthro. 18:169-170.

Weitoft, G.R., A. Hjern, B. Haglund, and M. Rosén. 2003. Mortality, severe morbidity, and injury in children living with single parents in Sweden: A population-based study. Lancet 361:289-295.

Werner, E.E. 1984. Child Care: Kith, Kin and Hired Hands. Baltimore: Univ. Park Press.

West-Eberhard, M.J. 2003. Developmental plasticity and evolution. Oxford: Oxford Univ. Press.

Wiessner, P. 2002. Hunting, healing and hxaro exchange: A long-term perspective on !Kung (Ju/'hoansi) large-game hunting. Evol. Hum. Behav. 23:407-436.

Whitten, A., V. Horner, and S. Marshall-Pescini. 2003. Cultural anthropology. Evol. Anthro. 2:92-105.

${ }^{1}$ It is noteworthy that cooperatively breeding tamarins gauge another individual's intentions in deciding on whether or not to share food (Hauser et al. 2004). Unfortunately, this pioneering study stands by itself so we do not yet have any comparative information about which other primates besides humans and tamarins do, and do not, share such abilities. 